\title{
Presence of novel triple mutations in the pvdhfr from Plasmodium vivax in Mangaluru city area in the southwestern coastal region of India
}

\author{
Shiny Joy ${ }^{1,3}$, Susanta K. Ghosh², Rajeshwara N. Achur ${ }^{3}$, D. Channe Gowda ${ }^{4}$ and Namita Surolia ${ }^{*}$
}

\begin{abstract}
Background: Genes encoding dihydrofolate reductase (dhfr) and dihydropteroate synthase (dhps) are the targets of sulfadoxine-pyrimethamine (SP) present in artemisinin based combination therapy (ACT; artesunate + sulfadoxine pyrimethamine) for Plasmodium falciparum. Although SP is generally not used to treat vivax infection, mutations in dhfr and dhps that confer antifolate resistance in Plasmodium vivax are common; which may be attributed to its sympatric existence with P. falciparum. Current study was aimed to determine the pattern of mutations in dhfr and dhps in P. vivax isolates from Mangaluru region.
\end{abstract}

Methods: A total of 140 blood samples were collected from P. vivax-infected people attending Wenlock Hospital Mangaluru during July 2014 to January 2016. Out of 140 isolates, 25 (18\%) and 50 (36\%) isolates were selected randomly for sequence analysis of pvdhfr and pvdhps genes respectively. Fragment of pvdhps and full length $p v d h f r$ were amplified, sequenced and analysed for single nucleotide polymorphisms. dhps was analysed by PCR-RFLP also, to detect the two specific mutations (A383G and A553G).

Results: Analysis of pvdhps sequences from 50 isolates revealed single and double mutants at 38 and $46 \%$ respectively. Three non-synonymous mutations (K55R, S58R and S117N) were identified for pvdhfr. Among these, K55R was detected for the first time.

Conclusions: The current study indicates that P. vivax dhps and dhfr mutant alleles are prevalent in this area, suggesting significant SP pressure.

Keywords: Dihydrofolate reductase, Dihydropteroate synthase, Single nucleotide polymorphisms, Restriction fragment length polymorphisms, Sulfadoxine/pyrimethamine, Mangaluru, India

\section{Background}

Anti-malarial drug resistance is a major public health issue in many countries. After the emergence of chloroquine resistance in Plasmodium falciparum, sulfadoxine-pyrimethamine (SP) drug combination is used widely especially in mixed infection cases. In both $P$. falciparum and Plasmodium vivax, combination of antifolate drugs target the folate metabolism by acting on two enzymes, dihydrofolate reductase ( $d h f r$ ) and dihydropteroate synthase (dhps). Mutations in these genes lead to SP

\footnotetext{
*Correspondence: surolia@jncasr.ac.in

${ }^{1}$ Molecular Biology and Genetics Unit, Jawaharlal Nehru Centre for Advanced Scientific Research, Jakkur, Bangalore, India

Full list of author information is available at the end of the article
}

resistance. Several mutations have been identified in $P$. vivax dhfr. Of these, mutations at codon $57,58,61,117$ and 173 are known to be associated with pyrimethamine resistance [1]. Similarly five point mutations at codon 382, 383, 512, 553 and 585 of $P$. vivax dhps are involved in sulfadoxine resistance. Of these, mutations at codons 383 and $553\left(\mathrm{~S}_{382} \mathrm{G}_{383} \mathrm{~K}_{512} \mathrm{G}_{553} \mathrm{~V}_{585}\right.$ genotype) were highly correlated with sulfadoxine resistance [2].

In India, $P$. vivax accounts for more than half of the malaria cases (53\%) [3]. Though some clinical cases of resistance have been reported [4-7], CQ remains the drug regimen for vivax malaria. Artemisinin-based combination therapy (ACT) is used for the treatment of mixed infection and complicated $P$. vivax cases [8]. Thus, 
analysis of $p v d h f r$ and $p v d h p s$ gene sequences predict the $\mathrm{SP}$ efficacy in a particular region.

Mangaluru, the coastal city of Karnataka, has a tropical climate, with over $6 \%$ mixed infection cases [9]. Although SP treatment is not recommended for $P$. vivax infections in this area, parasites get exposed to this drug when SP is given to $P$. falciparum and $P$. vivax mixed infection cases. The current study was aimed to analyse the polymorphisms in dhfr and dhps genes of P. vivax in this area.

\section{Methods}

\section{Sample collection and ethics}

The study was conducted at Wenlock District Hospital, Mangaluru city, located at the Southwestern coastal India in the Dakshina Kannada district in Karnataka state, India. Samples were collected from June 2014 to December 2015 after obtaining informed consents. A total of 140 mono-infection $P$. vivax positive patients were collected. Ethical clearance was obtained for all the patients. Out of 140 isolates, 25 (18\%) and 50 (36\%) isolates were selected randomly and included for the study. After confirming infections by expert microscopic examinations of Giemsa-stained thick and thin blood smears, and reconfirmed with bivalent rapid diagnostic test kit (Falcivax ${ }^{\circledR}$ from tulip, Goa), blood samples were collected on Whatman 3MM filter paper. Blood spots on filter papers were allowed to air-dry and then placed individually in plastic bags and stored at $-20{ }^{\circ} \mathrm{C}$ until processed. The study was approved by the Institutional Review Boards (IRB) of The Pennsylvania State University College of Medicine, Hershey, PA, USA, by incorporating approval from the ethics committee of Kuvempu University, Shivamogga, Karnataka, India. The IRB approved Protocol Number is 34148. The study designed was according to the NIH and ICMR ethical guidelines.

\section{DNA extraction and species confirmation}

Genomic DNA was extracted from filter paper spots as described earlier [10]. The extract was stored at $-20{ }^{\circ} \mathrm{C}$ until used. Amplification of SP resistance associated genes; the $P$. vivax dhfr and dhps genes from 25 to 50 isolates were amplified using primers and conditions as described earlier [2, 11]. For $d h f r$ amplification, PCR conditions used were initial denaturation at $95{ }^{\circ} \mathrm{C} / 30 \mathrm{~s}$, denaturation at $95{ }^{\circ} \mathrm{C} / 30 \mathrm{~s}$, annealing at $62{ }^{\circ} \mathrm{C} / 30 \mathrm{~s}$ and extension at $68^{\circ} \mathrm{C} / 60 \mathrm{~s}$ for 30 cycle and final extension at $68{ }^{\circ} \mathrm{C} / 5 \mathrm{~min}$. For $d h p s$, nested PCR strategy was used as described earlier [2]. Restriction digestion of dhps: to detect the mutations at 383 and 553, Msp1 and Msc1 restriction enzymes were used respectively. Restriction digestion was carried out by using previously described PCR-RFLP method [2]. The mutation at codon 383 was detected by restriction digestion with Msp1 enzyme. If the mutation is present at 383 codon (383 Gly), Msp1 cleaves the $703 \mathrm{bp}$ fragment to $655 \mathrm{bp}$ and $48 \mathrm{bp}$. The mutation at 553 was detected by restriction digestion with Msc1 enzyme and PCR product of $170 \mathrm{bp}$. If the mutation is present at codon 553 (553 Gly), Msc1 does not digest $170 \mathrm{bp}$ fragment, but it cleaves the $170 \mathrm{bp}$ fragment to 143 and 28 bp fragment if no mutation is present. The DNA fragments obtained after RFLP analysis were electrophoresed on 1 and 3\% agarose gels (Additional file 1: Figure S1).

\section{Sequence analysis}

Sequencing was performed on purified product of $711 \mathrm{bp}$ of $p v d h f r$ and $705 \mathrm{bp}$ of $p v d h p s$. The PCR products were extracted from gels using Gel Extraction kit (SigmaAldrich, St Louis, MO, USA) and sequenced. Sequencing of genes from each isolate was performed on an ABI Prism 377 DNA Sequencer equipped with semi adaptive version 3.0. Nucleotide sequences were analysed using blast and Bio Edit Sequence Alignment Editor and compared with reference sequences of Gen-Bank Accession Numbers X98123 and AY186730 for pvdhfr and pvdhps respectively. All PCR amplifications were carried out with a negative control (no template) and polymorphisms in these two genes were confirmed by reading both the forward and reverse strands.

\section{Results}

Plasmodium vivax dhfr and pvdhps gene polymorphisms

dhfr

Complete coding region of $d h f r$ from 25 isolates was amplified and sequenced. On comparison with reference strain, three different point mutations (K55R, S58R and $\mathrm{S} 117 \mathrm{~N}$ ) were observed. Novel mutation (K55R) was observed in $36 \%$ of the samples. Mutations S58R and S117N were observed in all the samples (100\%). Frequency distribution of mutation at each codon and haplotype distribution in $d h f r$ are given in Table 1 . Type 2 tandem repeat variation was observed in all the samples.

$\begin{aligned} & \text { Table } 1 \\
& \text { Frequency distribution of mutation at each codon } \\
& \text { and haplotype in pvdhfr gene }\end{aligned}$
\begin{tabular}{lcc}
\hline No & Aminoacid change & Isolates number (\%) \\
\hline 1. & K55R (AAG to AGG) & $9(36)$ \\
2. & S58R (AGC to AGG) & $25(100)$ \\
3. & S117N (AGC to AAC) & $25(100)$ \\
Haplotype & & \\
1. & No mutation (Wild type) & $0(0)$ \\
2. & Double mutant (58R117N) & $16(64)$ \\
3. & Triple mutant (55R58R117N) & $9(36)$ \\
\hline
\end{tabular}

Underlined font represents base change 


\section{dhps}

For dhps a total of 50 isolates were amplified and sequenced. Sequence analysis revealed two mutations A383G and A553G in different frequencies. Mutations at each codon and haplotype frequencies are shown in Table 2. Three different genotypes, $16 \%$ of wild type (SAKAV), 38\% of single mutant (SGKAV) and $46 \%$ of double mutant (SGKGV) were observed. Both sequencing and PCR-RFLP was done for majority of the isolates and revealed same result. None of the additional mutations identified by sequencing.

\section{Discussion}

Polymorphisms in two of the folate biosynthesis pathway genes $d h p s$ and $d h f r$ contribute to sulfadoxine and pyrimethamine drug resistance respectively in $P$. falciparum. Similar drug resistance mechanisms are present in $P$. vivax due to the conserved nature of the homologs of these two enzymes [12]. Mutations at five positions in $P$. vivax DHFR-thymidylate synthase gene (A15, N50, R58, N117, and I173) as determined by the secondary structure analysis are identified corresponding to 16,51 , 59,108 , and 164 respectively in $P$. falciparum. The $p f d-$ hfr primary mutation (S108N) combined with secondary mutations at codons $50,51,59$, and 164 lead to enhanced pyrimethamine resistance [13]. Similarly, mutations at codons 436, 437, 540, 581, and 613 of dhps lead to sulfadoxine resistance in $P$. falciparum [14]. Five mutations at homologous gene $p v d h p s$ have been identified at codons 382, 383, 512, 553 and 585. Among these, mutations at codon 383 and 553 are solely responsible for sulfadoxine resistance. Additional mutations confer higher levels of resistance $[2,15]$.

The current study reports the antifolate resistance in $P$. vivax infection, analysing $d h f r$ and dhps mutations in isolates collected from Mangaluru and its surrounding area. Analysis of point mutations in $d h f r$ among isolates from Indian sub-continent earlier revealed presence of four distinct genotypes: the wild, single mutant, double mutant, and quadruple mutant [16]. The current study reveals occurrence of only double and triple mutants, while none of the isolates are found to contain single or

Table 2 Frequency distribution of mutation at each codon and haplotype in pvdhps gene

\begin{tabular}{llr}
\hline No & Aminoacid change & Isolates number (\%) \\
\hline 1. & A383G (GCC to GGC) & $42(84)$ \\
2. & A553G (GCC to GGC) & $23(46)$ \\
Haplotype & & \\
1. & No mutation (wild type) & $8(16)$ \\
2. & Single mutant (383G) & $19(38)$ \\
3. & Double mutant (383G553G) & $23(46)$ \\
\hline
\end{tabular}

quadruple $d h f r$ mutations. No isolates carrying wild type allele and mutations at amino acids 58 and 117 of $d h f r$ were detected. The frequency of isolates carrying double mutations was found to be the highest as reported earlier from Chennai region from South India [16]. These mutations (in combination) are usually associated with resistance, due to slow clearance after SP treatment [17].

A novel mutation K55R is observed together with S58R and $5117 \mathrm{~N}$ accounting to $36 \%$ triple mutants. Presence of this haplotype consisting of these mutants is observed for the first time. $d h f r$ sequences from all the isolates revealed type 2 tandem repeat variants similar to previous observations reported from India [18, 19]. Type 1 tandem repeat variant was found to be associated with quadruple mutations and higher levels of resistance which can serve as a molecular marker to predict the risk of mutations in any geographical area of Indian subcontinent [16]. Since the presence of double mutations and type 2 tandem repeat variants are predominant in our study, the level of resistance may not be that high, however continuous monitoring and surveillance is essential to predict the emergence of drug resistance in this area. As previous studies have reported, prevalence of $d h f r$ mutant alleles are seen in the areas experiencing higher levels of SP pressure while wild type $d h f r$ genotype is maintained in the areas with no or little SP pressure [1, 18]. The presence of mutations in the current study is indicative of SP pressure in the area.

Plasmodium vivax dhps sequences from 50 isolates were analysed. Two resistance conferring mutations A383G and A553G are observed in isolates with 84 and $46 \%$ respectively. These SNPs attribute to increased sulfadoxine resistance levels [12]. Wild type $d h p s$ sequences (SAKAV genotype) were observed only in $16 \%$ isolates while single mutants (SGKAV) at $38 \%$ and double mutants (SGKGV) at $46 \%$ are observed. PCR-RFLP results corroborated similar trend. No additional mutations were detected by direct sequencing. Evaluation of these two markers ( $d h f r$ and $d h p s$ ) are important to predict the antifolate drug resistance in this area and this calls for continuous monitoring for deciding anti-malarial drug policy in the region.

\section{Conclusions}

The results indicate that since the isolates from this area are exposed to antifolate drugs they have developed mutations in their dhfr and dhps genes.

\section{Additional file}

Additional file 1: Figure S1. PCR-RFLP of the pvdhps gene. 


\section{Abbreviations}

SP: sulfadoxine-pyrimethamine; SNPs: single nucleotide polymorphisms; ACT : artemisinin-based combination therapy; CQ: chloroquine; RDT: rapid diagnostic test; PCR-RFLP: polymerase chain reaction-restriction fragment length polymorphisms; ICMR: Indian Council of Medical Research.

\section{Authors' contributions}

NS conceptualized and designed the study; SJ performed the study; NS analysed and interpreted the data; SJ wrote the manuscript; NS, DCG and SKG edited the manuscript; NS and DCG provided study resources. All authors read and approved the manuscript.

\section{Author details}

${ }^{1}$ Molecular Biology and Genetics Unit, Jawaharlal Nehru Centre for Advanced Scientific Research, Jakkur, Bangalore, India. ${ }^{2}$ Department of Biological Control, National Institute of Malaria Research, Poojanahalli, Bangalore, India. ${ }^{3}$ Department of Biochemistry, Kuvempu University, Shankaraghatta, Shivamogga District, Karnataka, India. ${ }^{4}$ Department of Biochemistry and Molecular Biology, The Pennsylvania State University College of Medicine, 500 University Drive, Hershey, PA 17033, USA.

\section{Acknowledgements}

We would like to thank Mr. A Bapaiaha for helping with sample collection. We also thank Mrs. Anitha C A, Corefacility, JNCASR, for gene sequencing and Dr. Suchetha Kumari, Department of Biochemistry, K. S. Hegde Medical Academy, NITTE University, Mangaluru, India, for her valuable suggestions.

\section{Competing interests}

The authors declare that they have no competing interests.

\section{Availability of data and materials}

The data used in this study is archived in corresponding authors university and available from the corresponding author upon reasonable request.

\section{Ethics approval and consent to participate}

The ethics committee of Kuvempu University, Shivamogga, Karnataka, India, and the Institutional Review Board of the Penn State University College of Medicine, USA, have approved this study. Informed written consent was obtained from all the study participants.

\section{Consent for publication}

Not applicable.

\section{Funding}

This work was supported by the Grant D43 TW008268 from the Fogarty International Center of the National Institutes of Health, USA, under the Global Infectious Diseases Program. The funders had no role in study design, data collection, and analysis, decision to publish, or preparation of the manuscript.

\section{Publisher's Note}

Springer Nature remains neutral with regard to jurisdictional claims in published maps and institutional affiliations.

Received: 14 February 2018 Accepted: 9 April 2018

Published online: 16 April 2018

\section{References}

1. Imwong M, Pukrittayakamee S, Re L, Letourneur F, Charlieu J, Leartsakulpanich $U$, et al. Novel point mutations in the dihydrofolate reductase gene of Plasmodium vivax: evidence for sequential selection by drug pressure. Antimicrob Agents Chemother. 2003;47:1514-21.

2. Imwong M, Pukrittayakamee S, Cheng Q, Moore C, Looareesuwan $\mathrm{S}$, Snounou G, et al. Limited polymorphism in the dihydropteroate synthetase gene (dhps) of Plasmodium vivax isolates from Thailand. Antimicrob Agents Chemother. 2005;49:4393-5.
3. Anvikar AR, Shah N, Dhariwal AC, Sonal GS, Pradhan MM, Ghosh SK, et al. Epidemiology of Plasmodium vivax malaria in India. Am J Trop Med Hyg. 2016:95:108-20.

4. Dua VK, Kar PK, Sharma VP. Chloroquine resistant Plasmodium vivax malaria in India. Trop Med Int Health. 1996;1:816-9.

5. Garg M, Gopinathan N, Bodhe P, Kshirsagar NA. Vivax malaria resistant to chloroquine: case reports from Bombay. Trans R Soc Trop Med Hyg. 1995;89:656-7

6. Kshirsagar NA, Gogtay NJ, Rajgor D, Dalvi SS, Wakde M, Gogtay NJ, et al. An unusual case of multidrug-resistant Plasmodium vivax malaria in Mumbai (Bombay), India. Ann Trop Med Parasitol. 2000;94:189-90.

7. Nandy A, Addy M, Maji AKBA. Monitoring the chloroquine sensitivity of Plasmodium vivax from Calcutta and Orissa, India. Ann Trop Med Parasitol. 2003:97:215-20.

8. Guidelines for diagnosis and treatment of malaria in India. Government of India. 2009. http://www.nvbdcp.gov.in/Doc/Guidelines_for_Diagn o-sis_Treatment.pdf. Accessed 14 Apr 2018.

9. Malaria in Mangaluru. Malaria site. http://www.malariasite.com/malar ia-mangaluru/. Accessed 2 Jan 2018.

10. Plowe CV, Djimde A, Bouare M, Doumbo O, Wellems TE. Pyrimethamine and proguanil resistance conferring mutations in Plasmodium falciparum dihydrofolate reductase: polymerase chain reaction methods for surveillance in Africa. Am J Trop Med Hyg. 1995;52:565-8.

11. Lu F, Wang B, Cao J, Sattabongkot J, Zhou H, Zhu G, et al. Prevalence of drug resistance-associated gene mutations in Plasmodium vivax in Central China. Korean J Parasitol. 2012;50:379-84.

12. Korsinczky M, Fischer K, Chen N, Baker J, Rieckmann K, Cheng Q. Sulfadoxine resistance in Plasmodium vivax is associated with a specific amino acid in dihydropteroate synthase at the putative sulfadoxine-binding site. Antimicrob Agents Chemother. 2004;48:2214-22.

13. Cortese JF, Plowe CV. Antifolate resistance due to new and known Plasmodium falciparum dihydrofolate reductase mutations expressed in yeast. Mol Biochem Parasitol. 1998;94:205-14.

14. Gregson A, Plowe CV. Mechanisms of resistance of malaria parasites to antifolates. Pharmacol Rev. 2005:57:117-45.

15. Triglia T, Wang P, Sims PF, Hyde JE, Cowman AF. Allelic exchange at the endogenous genomic locus in Plasmodium falciparum proves the role of dihydropteroate synthase in sulfadoxine-resistant malaria. EMBO J. 1998;17:3807-15.

16. Prajapati SK, Joshi H, Dev V, Dua VK. Molecular epidemiology of Plasmodium vivax anti-folate resistance in India. Malar J. 2011;10:102.

17. Barnadas C, Tichit M, Bouchier C, Ratsimbasoa A, Randrianasolo L, Raherinjafy $R$, et al. Plasmodium vivax dhfr and dhps mutations in isolates from Madagascar and therapeutic response to sulfadoxine-pyrimethamine. Malar J. 2008;7:35.

18. Imwong M, Pukrittakayamee S, Looareesuwan S, Pasvol G, Poirriez J, White NJ, et al. Association of genetic mutations in Plasmodium vivax dhfr with resistance to sulfadoxine-pyrimethamine: geographical and clinical correlates. Antimicrob Agents Chemother. 2001;45:3122-7.

19. Alam MT, Bora H, Bharti PK, Saifi MA, Das MK, Dev V, et al. Similar trends of pyrimethamine resistance-associated mutations in Plasmodium vivax and P. falciparum. Antimicrob Agents Chemother. 2007;51:857-63.

Ready to submit your research? Choose BMC and benefit from:

- fast, convenient online submission

- thorough peer review by experienced researchers in your field

- rapid publication on acceptance

- support for research data, including large and complex data types

- gold Open Access which fosters wider collaboration and increased citations

- maximum visibility for your research: over 100M website views per year

At $\mathrm{BMC}$, research is always in progress.

Learn more biomedcentral.com/submissions 